\title{
Mixed-Model Assembly Line Balancing in The Process of Assembling Trimming Area to Minimize Workstation Using RPW-MVM Method
}

\author{
Muhamad Ali Yusuf ${ }^{1 *}$, Dida Diah Damayanti ${ }^{2}$, and Murni Dwi Astuti ${ }^{3}$ \\ 1,2,3 Industrial Engineering, Telkom University
}

\begin{abstract}
The development of an industry that continues to move forward coupled with global competition and openness demands that the company continues to evolve and always make improvements in improving the performance of its production process. XYZ Corp is an automotive company based in Germany that produces premium cars, the car assembly process groove at $\mathrm{XYZ}$ Corp is a trimming line, mechanical line and finishing line, XYZ Corp produces A-model, B-model and C-model cars. At this time XYZ Corp not achieving the production target due to the car assembly cycle time on the trimming Line 1 area exceeds the specified takt time. Assembly line balancing is required in the trimming area using Mixed-Model Assembly Line Balancing Problem (MALBP) approach to minimize the number of workstation, in the Trimming area assembly line balancing study using the Ranked Positional Weighted with Moving Target (RPW-MVM) method. Alocation constraint should be added due to machine restrictions that cannot be moved. After assembly line balancing, there was a decrease in the number of workstations to 14 workstations with a line efficiency of $86 \%$ and balancing efficiency of $97 \%$.
\end{abstract}

\section{Introduction}

The development of the industrial that continues to move forward coupled with competition and global openness to meet consumer demand makes companies, especially automotive companies continue to grow and always make improvements. The development of the sales market is very competitive and oriented to customer satisfaction. For example, in the automotive industry, products are made based on several different models and features that are oriented to the customers wants. In an effort to fulfill the demand by building and maintaining assembly lines, the company made a single assembly line for several mixed models. In a situation like this, the problem of the balance of the assembly line will arise because of the demands for different models and features that vary with each product produced (Haq, Jayaprakash, \& Rengarajan, 2006).

$\mathrm{XYZ}$ Corp is a German automotive company that produces premium cars with high performance. Cars manufactured by XYZ Corp has several types of car products such as model A, model B, and model C. The flow of the car assembly process at XYZ Corp is a

* Corresponding author: aliyusuf.ay30@gmail.com 
trimming line and a mechanical line. While the engine, door, tire, and dashboard subassembly process is an assembly sub-process on the assembly line in the production department, according to Kumar and Mahto (2013) the assembly line model at XYZ Corp has the characteristics of a mixed-model assembly line because the company produces several types of products on 1 track and there is no setup time for changes in the types of products assembled.

The company can only meet the production target of $90 \%$, the processing time for each work station in trimming is different, Figure 1 is a graphical representation of the processing time in the trimming area. Based on the graph data in Figure 1, it can be seen that at some work stations in the trimming area there is a processing time that exceeds the specified takt time, resulting in an unbalanced trimming assembly line which results in some work station bottlenecks and idle time so that the production target is not reached. Therefore it is necessary to balance the workload in the assembly area. This study aims to design a proposed assembly line with an optimal number of work stations with better line efficiency and balancing performance index.

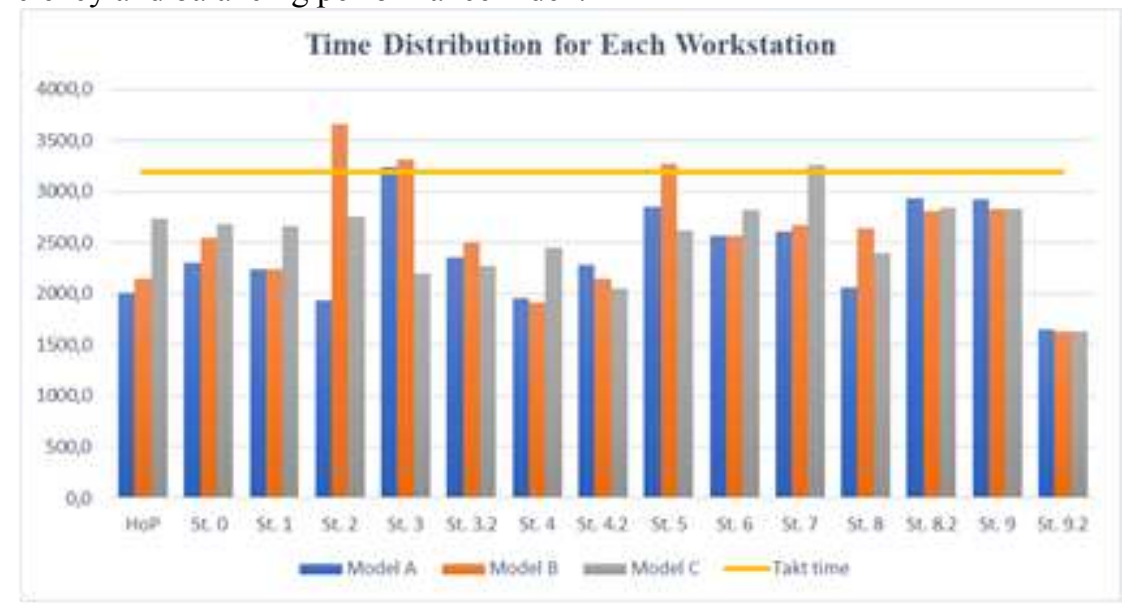

Fig. 1. Time Distribution for Each Workstation

This study focuses on the imbalance of assembly lines. The problem of the imbalance of the assembly line is due to the uneven allocation of workload and the time at several stations that exceed takt time as found in Figure 1. In this study, the balancing of assembly lines is a mixed-model, where assembly lines can produce different models, with adaptability to demand with high levels of efficiency (Reginato et al., 2016). The main purpose of balancing assembly lines according to Eryuk et al (2008) is to minimize the number of work stations with predetermined cycle times or minimize cycle times with the number of work stations that have been determined.

Research "The Design of PC300 Type Hydraulic Excavator Assembly Line System with Genetic Algorithm Method" conducted by Andri Amir (2008) found an increase in productivity from 12 units/day to 13 units/day. Research conducted by Eryuk et al. (2008) regarding "Assembly Line Balancing in a Clothing Company", found that balancing assembly lines using the Ranked Positional Weight (RPW) method resulted in a more optimal number of work stations and line efficiency compared to line balancing using the method Probabilistic Balancing Line. Research conducted by Amen (2001) regarding the solution of assembly-line problems using the heuristic method, found that the heuristic ranked positional weight method has stable results when faced with problems in the real world. Balancing mixed-model assembly lines conducted by Reginato et al. (2016) examines and balances workloads with 7 product models using ranked positional weight 
with moving target (RPW-MVM) method, the results obtained after workload balancing is increased capacity, line efficiency and balancing efficiency.

Balancing mixed-model assembly lines conducted by Reginato et al. (2016) examines and balances workloads with 7 product models using ranked positional weight with moving target (RPW-MVM) method, the results obtained after workload balancing is incrThe development carried out by Reginato et al. (2016) developed the RPW method in solving problems in the assembly line development, solving assembly line problems using the RPW method which is purely regulated with predetermined cycle times, so that accumulated imbalances can produce assembly line performance. less well, in the RPW-MVM method, there is a limitation of moving target value (MVM) which is used as a reference in balancing and allocating work elements at work stations so that the assembly line is maintained more smoothly and provides a better performance value. eased capacity, line efficiency and balancing efficiency.

This study aims to determine the optimal number of work stations so that it can increase the value of line efficiency and balancing efficiency in the trimming area.

\section{Research Method}

\subsection{Assembly Line Balancing}

Assembly line balancing Is a task allocation procedure, where tasks are distributed equally for each assembly work station so that the workload of operators at each work station is balanced (RAJA, 2015). Balance assembly lines are used generally to improve the assembly process for serial work stations. Assembly line balancing is a technique that is often used by industries that want to implement lean manufacturing systems (Kumar and Mahto, 2013). Measures of efficiency (operational performance) of assembly lines can be measured based on (Damayanti and Toha, 2012):

1. Total work stations, each work station will require operating costs, called operational costs.

2. Idle time is a time that is avoided in the context of the efficiency of the assembly line and will result in idle time costs.

3. Waiting time, waiting time in the process is calculated as waiting time cost.

The purpose of balancing assembly lines according to Scholl (1995) is, as follows:

a. Reducing the number of work stations $(\mathrm{m})$ with a predetermined cycle time.

b. Reduce cycle time with the number of work stations that have been determined.

c. Improve line efficiency.

d. Look for a feasible solution with specified cycle time and number of work stations.

\subsection{Ranked Positional Weight with Moving Target (RPW-MVM)}

Solving line balancing problems on assembly lines using the pure RPW method is set with a predetermined cycle time, so that in allocating work elements to the workstation based on a fixed cycle time, this will result in allocating work elements at each workstation having accumulated imbalances which usually produces poor assembly line performance, to anticipate accumulated imbalances with fixed target limits / fixed cycle times the allocation of work elements must be allocated anywhere and anytime so that line balancing methods are developed on assembly lines based on weighting with moving targets or Moving-Target (MVM). Moving-Target (MVM) calculations on assembly lines are carried out at each work station and balancing assembly lines based on the number of work stations that are then Moving-Target (MVM) values are used as a reference for balancing the allocation of 
work elements at work stations. Moving-Target (MVM) calculations in the assembly line balancing process will make it easier to configure work stations by allocating work elements in a balanced manner to a predetermined work station (Reginato et al, 2016).

\subsection{Performance Indicator}

The balancing analysis of assembly lines generated from the RPW-MVM method used is as follows:

1. Line Efficiency (LE)

Line Efficiency (LE) is an indicator to measure the use of assembly lines that will have an impact on aspects of economic evaluation.

LE : line efficiency

$$
L E=\frac{\sum_{i=1}^{k} \mathrm{ST}_{i}}{K . C T} \cdot 100 \%
$$

$\mathrm{ST}_{i}:$ time of the i workstation

$\mathrm{K}$ : number of work stations

$\mathrm{CT}$ : cycle time

2. Balancing Efficiency

Balancing efficiency is an indicator that measures the quality of the allocation of work elements to workstations which has an impact on increasing production levels.

$S j^{-}$: Total station time weighted average

$$
B E=\left(1-\frac{\sum_{j=1}^{W} \mid \overline{S_{J}}-\text { Sav } \mid}{W \times \operatorname{Sav}}\right) \times 100
$$

$W \quad$ : Number of workstations

Sav : Average station time

\subsection{Alocation Constraint}

In the assembly process in the trimming area there are several allocation constraint, this limitation is due to machine restrictions that cannot be moved, some work processes or elements that have allocation constraint including:

a. Work elements C22, C21, C20, C19, C18, C17, C14, C11, C12, C16, C15, C13, C23, $\mathrm{C} 10, \mathrm{C} 2, \mathrm{C} 8, \mathrm{C} 7, \mathrm{C} 6, \mathrm{C} 1$ must be done at station 3.

b. K2 and K12 work elements must be worked on the same station.

c. Work element A2 must be worked on station 1

\section{RPW-MVM Model}

\subsection{Assembly Line Model}

The following model assembly lines at PT. XYZ has the characteristics of mixed-models (Raja, 2015), namely assembly lines making products with several variants, where the operation of work for similar product variants for different variants.

The measured performance indicators are:

a. Number of work stations

b. Line efficiency

\subsection{Balance of the Existing Assembly Line}

The following is the existing performance index information:

1. The number of existing assembly work stations is 15 work stations. 
2. The assembly line working time is 25500 seconds/day, cycle time is 3662 seconds/unit, so the capacity is 7 units/day.

3. The assembly line efficiency is $81 \%$ and balancing efficiency is $90 \%$.

\subsection{Calculation procedure using RPW-MVM}

The following are the calculation procedure steps using the RPW-MVM method to balance workload:

1. The first step is to make a combined precedence diagram for all work elements in each model that is worked on the existing work station, for details can be seen on Figure. 3.

2. Next, calculate the proportion of demand. In balancing assembly lines with many models, each model has a different processing time. The average processing time of each model needs to be defined by determining the proportion of demand.

$$
\mathrm{pdm}=\mathrm{dm} / \mathrm{D}
$$

Where, $\mathrm{dm}$ is product demand in period $\mathrm{p}$, where model $\mathrm{m}=1, \ldots \mathrm{M}$; and $\mathrm{D}$ is the total demand for all models produced. The proportion of demand for each model, the proportion of demand for model A models is $43.5 \%$, model B is $27.4 \%$ and model $\mathrm{C}$ is $29.1 \%$.

3. Calculate cycle time (TC) / takt time based on total production demand. Takt time is 3187.5 seconds/unit, the allocation of work elements must be under takt time.

$$
T c=\frac{\text { waktu tersedia pada periode } p}{\text { total permintaan pada periode } p}
$$

4. Calculate the average process time weight $(\mathrm{tk} \overline{)}$ and Average Station Time Total $(S j \overline{)}$ to allocate work elements to RPW-MVM because this method takes into account all models of a mix-model assembly line.

$$
\begin{aligned}
\mathrm{tk}^{-} & =\sum_{m=1}^{N} \mathrm{pd}_{\mathrm{m}} \mathrm{tk}_{m} \\
\mathrm{~S}^{-} & =\sum_{k € j} \mathrm{tk}^{-}
\end{aligned}
$$

5. Perform RPW calculations for each work element by summing the tk of the preceding process based on the combined precedence diagram.

6. Sort according to the weighting of RPW.

7. Calculate the minimum number of work stations (MinW).

$$
\begin{aligned}
& \mathrm{CTT}_{\mathrm{m}}=\sum_{k=1}^{N} \mathrm{tk}_{\mathrm{m}} \\
& M i n W=\frac{\mathrm{CTT}_{\mathrm{m}}}{T c}, \mathrm{~m}=1, \ldots, \mathrm{M}
\end{aligned}
$$

8. Determine the number of work stations $\mathrm{j}=\mathrm{w}$.

9. Calculate the moving target number (MVM) for each work station $(\mathrm{MVMj}, \mathrm{m}=1, \ldots ., \mathrm{M})$.

$$
\begin{array}{r}
\mathrm{CTA}_{\mathrm{j}, \mathrm{m}}=\mathrm{CTT}_{\mathrm{j}+1, \mathrm{~m}}+\mathrm{S}_{\mathrm{j}, \mathrm{m}} \\
M V M_{\mathrm{j}, \mathrm{m}}=\frac{\mathrm{CTT}_{\mathrm{m}}-\mathrm{CTA}_{j+1, m}}{\operatorname{Min} W-(\operatorname{Min} W-j)}
\end{array}
$$

10. Allocating work elements for each model based on RPW weighting values by taking into account the combined precedence diagram and the average weight of the work station $(S j \overline{)}$, allocation of work elements for each work station for all models does not exceed cycle time / takt time $(\mathrm{SJ}, \mathrm{m}=1, \ldots . \mathrm{M} \leq \mathrm{Tc}$

11. Repeat the allocation of work elements until the work elements for each model cannot be moved back.

12. Determine $(j=j-1)$ and do reconsideration $M V M j, m=1, \ldots, M$.

13. The next step is to validate the level of inequality, that is if ((major MVM j, $m=1, \ldots$, $\mathrm{M}) \leq \mathrm{Tc})$ then do the next step, if $(($ major MVM $\mathrm{j}, \mathrm{m}=1, \ldots, \mathrm{M}) \geq \mathrm{Tc})$ then repeat step 8 by calculating $(\mathrm{MinW}=\mathrm{MinW}+1)$ and repeating the allocation of work elements and then repeating calculations from steps 10 to 13 until all elements of the work are distributed. 


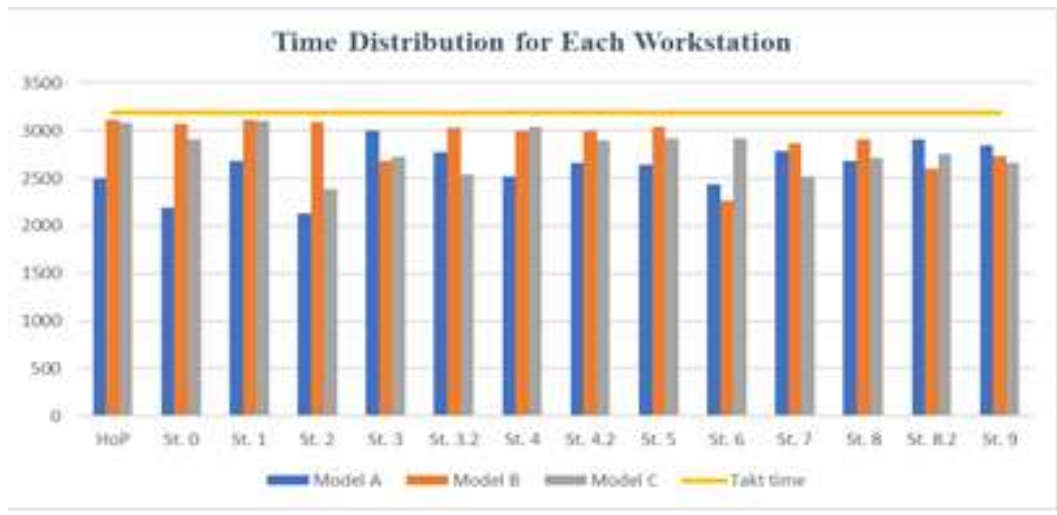

Fig. 2. Time Distribution for Each Workstation after Balancing

\section{Conclusions}

Based on the results of the calculation and reallocation of work elements for each work station in the trimming area, the optimal number of work stations is found in 14 work stations, with the proposed performance assembly line performance better than the performance index of the existing assembly line. A comparison of proposed and existing performance indexes can be seen in Table 1. After reallocation for each work element, the graph of time distribution for each work station can be seen in Figure 2.

Table 1. Performance Index Comparison

\begin{tabular}{llcc}
\hline & & Current Balancing & New Balancing RPW- MVM \\
\hline \multirow{5}{*}{ Variable } & Time Available in the period (sec) & 25500 & 25500 \\
& Demand (parts/day) & 8 & 8 \\
& Cycle time (sec) & 3187,5 & 3187,5 \\
& $\operatorname{Tg}(\mathrm{min})$ & 3662 & 3119 \\
\hline \multirow{3}{*}{ Indicator } & Amount of AL workstations & 15 & 14 \\
& Line Efficiency & $70 \%$ & $88 \%$ \\
& Balancing efficiency (BE) & $90 \%$ & $97 \%$ \\
\hline
\end{tabular}

\section{References}

1. A. Amir, Peranc. Sist, Keseimbangan Lini Perakitan Hydraul. Excav. Tipe PC300 Dengan Metod. Algoritm. Genet. (2008)

2. A. N. Haq, K. Rengarajan, and J. Jayaprakash, Int. J. Adv. Manuf. Technol. 28, 337 (2006)

3. D. D. Damayanti and I. S. Toha, in IEEE International Conference on Industrial Engineering and Engineering Management. (2012), pp. 568-572

4. G. Reginato, M. J. Anzanello, and A. Kahmann, Gest. E Prod. 23, 294 (2016)

5. M. Amen, Int. J. Prod. Econ. 69, 255 (2001)

6. N. Boysen, M. Fliedner \& M. Scholl, ISSN, Assembly line balancing: Which model to use when? (2006), pp. 1611-1311

7. N. Kumar and D. Mahto, Glob. J. Res. Eng. 13, 807 (2013)

8. R. RAJA, Assem. Line Des. Balanc. (n.d.) 
9. S. H. Eryuruk, F. Kalaoglu, and M. Baskak, Fibres Text. East. Eur. 16, 93 (2008) pp. 66

10. T. Baroto, Perencanan Dan Pengendalian Produksi (Ghalia Indonesia, Jakarta, 2002) 


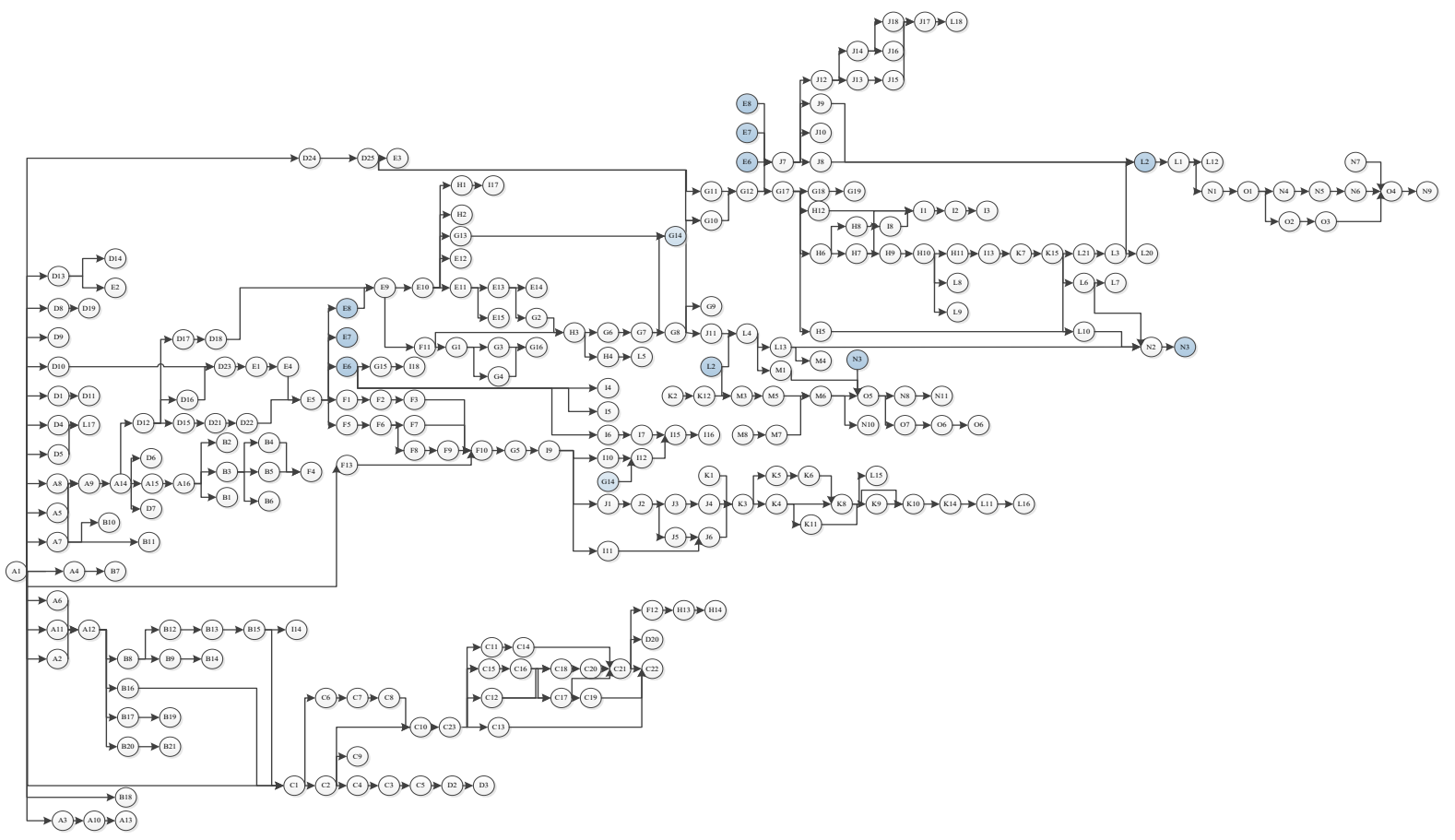

Figure 3. Precedence Diagram 
Table 2. Work Element

\begin{tabular}{|c|c|l|l|l|l|l|}
\hline & & \multicolumn{3}{|c|}{ Model } & \multirow{2}{*}{ RPW } \\
\cline { 3 - 6 } No & Predesesor & A & B & C & & \\
\hline A1 & & 35 & 35 & 35 & 35 & 35 \\
\hline A2 & A1 & 350 & 360 & 762 & 473 & 508 \\
\hline A3 & A1 & & 80 & & 22 & 57 \\
\hline A4 & A1 & 30 & 40 & & 24 & 59 \\
\hline A5 & A1 & 33 & 60 & 80 & 54 & 89 \\
\hline A6 & A1 & 72 & 55 & 60 & 64 & 99 \\
\hline A7 & A1 & 105 & 105 & 95 & 102 & 137 \\
\hline A8 & A1 & 58 & 58 & 80 & 64 & 99 \\
\hline A9 & A8, A5, & 134 & 140 & 140 & 137 & 393 \\
\hline A10 & A1, A3 & 458 & 458 & 458 & 458 & 515 \\
\hline A11 & A1 & & & 80 & 23 & 58 \\
\hline A12 & A6, A11, & 125 & 145 & 262 & 170 & 765 \\
\hline A13 & A10 & 45 & 45 & 45 & 45 & 560 \\
\hline A14 & A9 & 244 & 244 & 244 & 244 & 637 \\
\hline A15 & A14 & 280 & 280 & 280 & 280 & 917 \\
\hline A16 & A15 & 43 & 43 & 43 & 43 & 960 \\
\hline B1 & A16 & 42 & & 42 & 30 & 990 \\
\hline B2 & A16 & 40 & 40 & 40 & 40 & 1000 \\
\hline B3 & A16 & 90 & 50 & 80 & 76 & 1036 \\
\hline B4 & B3 & 90 & & & 39 & 1075 \\
\hline B5 & B3 & 93 & 93 & 100 & 95 & 1131 \\
\hline B6 & B3 & 57 & 48 & 80 & 61 & 1097 \\
\hline B7 & A4 & 135 & 120 & 110 & 124 & 183 \\
\hline B8 & A12 & 120 & 120 & 160 & 132 & 897 \\
\hline B9 & B8 & 75 & 75 & 170 & 103 & 999 \\
\hline B10 & A7 & 155 & & 110 & 99 & 237 \\
\hline B11 & A7 & 300 & 370 & 340 & 331 & 468 \\
\hline B12 & B8 & 120 & 120 & 95 & 113 & 1009 \\
\hline B12 & 480 & 480 & 550 & 500 & 1510 \\
\hline
\end{tabular}

\begin{tabular}{|c|c|c|c|c|c|c|}
\hline \multirow{2}{*}{ No } & \multirow{2}{*}{ Predesesor } & \multicolumn{3}{|c|}{ Model } & \multirow{2}{*}{ Tk } & \multirow{2}{*}{ RPW } \\
\hline & & A & B & $\mathrm{C}$ & & \\
\hline $\mathrm{C} 13$ & $\mathrm{C} 23$ & 10 & 10 & 10 & 10 & 2590 \\
\hline $\mathrm{C} 14$ & $\mathrm{C} 11$ & 17 & 17 & 17 & 17 & 2981 \\
\hline $\mathrm{C} 15$ & $\mathrm{C} 23$ & 33 & 33 & 33 & 33 & 2613 \\
\hline $\mathrm{C} 16$ & $\mathrm{C} 15$ & 120 & 120 & 120 & 120 & 2733 \\
\hline $\mathrm{C} 17$ & $\mathrm{C} 12, \mathrm{C} 16$ & 70 & 70 & 80 & 73 & 2986 \\
\hline $\mathrm{C} 18$ & $\mathrm{C} 12, \mathrm{C} 16$ & 135 & 135 & 160 & 142 & 3055 \\
\hline C19 & $\mathrm{C} 17$ & 120 & 120 & 120 & 120 & 3106 \\
\hline $\mathrm{C} 20$ & $\mathrm{C} 18$ & 150 & 140 & 60 & 121 & 3176 \\
\hline $\mathrm{C} 21$ & $\begin{array}{c}\mathrm{C} 14, \mathrm{C} 20 \\
\mathrm{C} 17\end{array}$ & 360 & 360 & 320 & 348 & 3999 \\
\hline $\mathrm{C} 22$ & $\begin{array}{c}\mathrm{C} 21, \mathrm{C} 13, \\
\mathrm{C} 19\end{array}$ & 40 & 40 & 40 & 40 & 4169 \\
\hline $\mathrm{C} 23$ & $\mathrm{C} 10$ & & & 388 & 113 & 2580 \\
\hline D1 & Al & 96 & 131 & 96 & 106 & 141 \\
\hline D2 & $\mathrm{C} 5$ & 60 & 95 & 80 & 75 & 2603 \\
\hline D3 & D2 & 24 & 65 & 30 & 37 & 2640 \\
\hline D4 & Al & 34 & 69 & 34 & 44 & 79 \\
\hline D5 & A9 & 40 & 85 & 50 & 55 & 448 \\
\hline D6 & A14 & 122 & 157 & 166 & 144 & 781 \\
\hline D7 & A14 & 140 & 175 & 140 & 150 & 787 \\
\hline D8 & A1 & 50 & 85 & 80 & 68 & 103 \\
\hline D9 & Al & 75 & 110 & 75 & 85 & 120 \\
\hline D10 & A1 & 28 & 63 & 28 & 38 & 73 \\
\hline D11 & D1 & 24 & 59 & 24 & 34 & 174 \\
\hline D12 & A14 & 80 & 115 & 80 & 90 & 727 \\
\hline D13 & Al & 326 & 361 & 326 & 336 & 371 \\
\hline D14 & D13 & 50 & 85 & 70 & 65 & 436 \\
\hline D15 & D12 & & 115 & & 32 & 758 \\
\hline D16 & D12 & & 253 & 120 & 104 & 831 \\
\hline D17 & D12 & & 169 & 134 & 85 & 812 \\
\hline D18 & D17 & 150 & 245 & 280 & 214 & 1026 \\
\hline
\end{tabular}




\begin{tabular}{|c|c|c|c|c|c|c|}
\hline \multirow{2}{*}{ No } & \multirow{2}{*}{ Predesesor } & \multicolumn{3}{|c|}{ Model } & \multirow{2}{*}{ Tk } & \multirow{2}{*}{ RPW } \\
\hline & & $\mathbf{A}$ & B & C & & \\
\hline B14 & B9 & 60 & 60 & & 43 & 1042 \\
\hline B15 & B13 & 445 & 445 & 505 & 462 & 1972 \\
\hline B16 & A12 & & 350 & & 96 & 861 \\
\hline B17 & A12 & & 110 & & 30 & 795 \\
\hline B18 & $\mathrm{A} 1$ & & 15 & & 4 & 39 \\
\hline B19 & B17 & & 50 & & 14 & 809 \\
\hline B20 & A12 & & & 100 & 29 & 794 \\
\hline B21 & B20 & & & 152 & 44 & 838 \\
\hline $\mathrm{C} 1$ & B16, B15 & 120 & 120 & & 85 & 2068 \\
\hline $\mathrm{C} 2$ & $\mathrm{C} 1$ & 237 & 237 & 237 & 237 & 2305 \\
\hline $\mathrm{C} 3$ & $\mathrm{C} 4$ & 207 & 207 & 207 & 207 & 2517 \\
\hline $\mathrm{C} 4$ & $\mathrm{C} 2$ & & 18 & & 5 & 2310 \\
\hline $\mathrm{C} 5$ & $\mathrm{C} 3$ & 15 & 15 & & 11 & 2528 \\
\hline C6 & $\mathrm{C} 1$ & 100 & 110 & & 74 & 2142 \\
\hline C7 & C6 & 50 & 50 & & 35 & 2177 \\
\hline $\mathrm{C} 8$ & $\mathrm{C} 7$ & 60 & 60 & & 43 & 2220 \\
\hline C9 & $\mathrm{C} 2$ & 24 & & & 10 & 2316 \\
\hline $\mathrm{C} 10$ & $\mathrm{C} 2, \mathrm{C} 8$ & 40 & 40 & 40 & 40 & 2467 \\
\hline $\mathrm{C} 11$ & $\mathrm{C} 23$ & 275 & 275 & 650 & 384 & 2964 \\
\hline $\mathrm{C} 12$ & $\mathrm{C} 23$ & 180 & 180 & 180 & 180 & 2760 \\
\hline
\end{tabular}

\begin{tabular}{|c|c|l|l|l|l|l|}
\hline \multirow{2}{*}{ No } & \multirow{2}{*}{ Predesesor } & \multicolumn{3}{|c|}{ Model } & \multirow{2}{*}{ Tk } & RPW \\
\cline { 3 - 5 } D19 & D8 & 160 & & 100 & 99 & 202 \\
\hline D20 & C21 & 190 & 245 & 230 & 217 & 4216 \\
\hline D21 & D15 & 170 & 205 & 200 & 188 & 946 \\
\hline D22 & D21 & 146 & 181 & 160 & 160 & 1106 \\
\hline D23 & D16, D10 & & 85 & 50 & 38 & 906 \\
\hline D24 & A1 & 70 & 105 & & 59 & 94 \\
\hline D25 & D24 & & 535 & 240 & 216 & 311 \\
\hline E1 & D23 & 70 & 55 & 70 & 66 & 972 \\
\hline E2 & D13 & 115 & 100 & 115 & 111 & 481 \\
\hline E3 & D25 & 145 & 130 & & 99 & 409 \\
\hline E4 & E1 & 30 & 25 & 20 & 26 & 998 \\
\hline E5 & D22, E3, & 705 & 705 & 600 & 674 & 2052 \\
\hline E6 & E5 & 180 & 165 & 50 & 138 & 2190 \\
\hline E7 & E5 & 130 & 115 & & 88 & 2140 \\
\hline E8 & E5 & 240 & 265 & 200 & 235 & 2287 \\
\hline E9 & $\begin{array}{c}\text { D18, E5, } \\
\text { D9 }\end{array}$ & 520 & 505 & 450 & 496 & 3166 \\
\hline E10 & E9 & 360 & 370 & 250 & 331 & 3497 \\
\hline E11 & E10 & 265 & 265 & & 188 & 3685 \\
\hline E12 & E10, E2 & 90 & 75 & 90 & 86 & 4029 \\
\hline E13 & E11, E12 & 350 & 335 & 300 & 331 & 4549 \\
\hline & & & & & \\
\hline
\end{tabular}

